\title{
Socio-technological authentication
}

\author{
Peter Lugosi \\ Oxford School of Hospitality Management \\ Oxford Brookes University \\ Oxford \\ United Kingdom \\ E-mail: plugosi@brookes.ac.uk
}

This is the final accepted version. Published as:

Lugosi, P. (2016) Socio-technological authentication. Annals of Tourism Research, Vol. 58, pp. 100-113, 10.1016/i.annals.2016.02.015.

Please consult the final version if citing.

Highlights

- Conceptualises tourism knowledge configurations as experiential objects

- Experiential objects are delineated through human cognition and computing algorithms

- Qualities of experiential objects are performed by human and non-human actors

- Authentication is the qualification of value in socio-technological networks

- Authentication involves visibility, obscuration and selective (de)coupling mechanisms

\begin{abstract}
This paper proposes a socio-technological approach to conceptualising the processes of authentication in technology-saturated society. It argues that authentication involves the inscription of value to objects, places, actions and experiences. Consequently, authentication processes in tourism should be understood through a 'market practices' conception of human-technology interactions. Markets are conceived as socio-technical performative arrangements in which goods and services are objectified and brought together in a single space where their values are negotiated. The paper introduces the notion of 'experiential objects' to conceptualise configurations of tourism-related knowledge, which are captured, transformed and retransmitted through human and technological practices. Moreover, it explores how the value of such objects are produced and qualified through the networked interactions of human and non-human actors.
\end{abstract}

Keywords: Actor-network-theory; authenticity; experience; non-human actors; socialmedia; technology 


\section{Introduction}

Tourism academics continue to be fascinated by authenticity and there is a long history of debate that has attempted to de- and re-construct the concept (Brown, 2013; Chhabra, 2010, 2012; Olsen, 2002; Selwyn, 1996; Wang, 1999). Discussion has recently shifted from defining authenticity and distinguishing between forms of authenticity to examination of authentication: the processes by which qualities of authenticity are constructed, assigned, evaluated or experienced (cf. Belhassen, Caton, \& Stewart, 2008; Chhabra, 2005; Cohen \& Cohen, 2012; Xie, 2011). This conceptual paper advances this line of enquiry by contending that the process of authentication is the designation, calculation and qualification of worth or value. Moreover, it uses a socio-technological, 'marketpractices' approach to examine authentication (Çalışkan \& Callon, 2010; Callon \& Muniesa, 2005; Callon, Méadel, \& Rabeharisoa, 2002; Latour, 2005; Muniesa, Millo, \& Callon, 2007). The approach adopted to conceptualise authentication thus offers a framework for understanding its processes rather than providing a singular, reductive and fixed account of authentication, its components and their configuration. Significantly, the paper contributes to knowledge by developing and advocating a perspective on the study of authentication that accounts more fully for the role of technology in valuing the places, practices and objects entangled in the production and consumption of tourism. Furthermore, the paper shifts the focus on to the processes of authentication as value claims are enacted by a network of actors, and it explores the performative techniques through which notions of authenticity may be inscribed.

The socio-technological market-practices approach adopted here draws directly from Actor-Network-Theory (ANT) (Latour, 2005), which is increasingly being utilised in tourism studies (e.g. Ren, 2011; Tribe, 2010; Paget, Dimanche, \& Mounet, 2010; Van der Duim, Ren, \& Jóhannesson, 2012, 2013). The methods and underlying assumptions of ANT and its applicability to tourism have been discussed in detail elsewhere and I do not intend to rehearse them at length here (cf. Jóhannesson, 2005; Jóhannesson, Van der Duim, \& Ren, 2015; Van der Duim, 2007). However, it is useful to briefly stress the key characteristics of ANT to show their relevance to the current undertaking.

A key underlying ontological assumption of ANT concerns the conception of 'entities', which may refer to 'facts', objects, technologies, institutions etc., existing or emerging through performative practice within networks of relations. Entities are socio-materially constructed, which means that, in analytical or empirical terms, they are never 'finished' but are (re)constructed or (re)assembled through performative processes. Importantly, nonhuman 'actants' or 'actors' are deemed to have power and agency insofar as they take part in the construction of the world. Socio-material actors are enrolled and their performative roles and significance are inscribed through networked relations (Latour, 2005).

The ANT approach is particularly useful for conceptualising authentication because it forces us to examine how multiple socio-technological agencies are enrolled in assembling or constructing notions of authenticity. Moreover, fundamental to such a conception of authentication is that it is approached as a non-linear process in which heterogeneous actors interact to qualify and contest value claims about places, objects, actions and experiences. Lastly, ANT recognises the interaction of human and non-human 'actors'. Previous studies of authenticity and authentication have argued that tourists utilise technologies such as social media to communicate their positions, values and experiences (Mkono, 2012a, 2012b, 2013; Osman, Johns and Lugosi, 2014). However, within these studies, social networking sites and technologies were treated as neutral communication 
media. In contrast, the approach advocated here proposes to examine the ability of the media platform, and pervasive computing technology more broadly, to shape the processes of authentication.

I argue that socio-technological arrangements produce experiential objects, the qualities of which are defined and redefined through their production. Within this context, the term 'object' does not refer simply to physical items, but refers instead to objectified configurations of knowledge, which can involve places, people, objects, actions, sensations and experiences, that are delineated through human and non-human valuation practices and algorithmic methods.

I argue that authentication occurs through the delineation and qualification of these objects as their value is transformed, calculated and negotiated through networks of interactions. Importantly, I adopt a conception of power as being distributed in or enacted through socio-technological arrangements. In discussing the role of power in authentication, authors have previously emphasised the agency of consumers, experts, political bodies and tourist organisations in general (see e.g. Belhassen et al., 2008; Chhabra, 2005, 2010, 2012; Cohen \& Cohen, 2012; Martin, 2010; Lau, 2010; Steiner \& Reisinger, 2006; Wang, 2007; Xie $\&$ Wall, 2002). However, they have largely ignored the role of other intermediary agencies, specifically technology companies, the algorithmic knowledge they deploy, the infrastructure they operate and the pervasive computer technology through which tourists engage with experiential objects. This paper seeks to address this gap in current understanding by proposing an alternative perspective which accounts more fully for the role of technology in authentication value claims

The paper begins by reviewing the notion of authentication and its uses in conceptualising the ascription of qualities to tourism practices. The subsequent section considers human-technology interactions to stress the entanglement of human cognitive processes, social relations and pervasive computing technology. Exploring these interactions paves the way for a detailed discussion of market practices, with particular emphasis on the processes through which values are ascribed and negotiated in market-type relations. In the following section I introduce the notion of experiential objects and proceed to examine the processes through which multiple actors enact authentication. Within this discussion I consider how three different techniques: foregrounding, obscuration and the selective coupling-decoupling of information, may be deployed in authentication. I close the discussion by suggesting how future research may examine different aspects of sociotechnological processes in conjunction to gain a richer understanding of authentication practices in contemporary technology-saturated society.

\section{Authentication in tourism}

Debates concerning definitions of authenticity and its utility in understanding tourist motivations and tourism experiences have highlighted a number of contradictory trajectories (MacCannell, 1999; Olsen, 2002; Wang, 1999). On the one hand, academics have come to develop increasingly incompatible conceptions of authenticity, particularly as they relate in different contexts to objects, cultures, heritage attractions or embodied tourism experiences (Reisinger \& Steiner, 2006; Steiner \& Reisinger, 2006; Wang, 1999). On the other hand, studies have also repeatedly stressed that authenticity continues to matter for tourists, businesses and destinations (Belhassen \& Caton, 2006; Frochot \& Batat, 2013; Mkono, 2012a; Pine \& Gilmore, 2008). The search for authenticity may be key push or pull 
factors motivating tourists (MacCannell, 1999; Kim \& Jamal, 2007). Notions of authenticity also shape decision making and evaluation of tourism experiences (Belhassen et al., 2008; Osman et al., 2014).

In light of these issues, recent debates concerning authenticity and tourism have purposefully moved away from discussing different types of authenticity to examining how values or qualities of authenticity are assigned to tourism objects and experiences; in other words, how they are 'authenticated' (Chhabra, 2005; Mkono, 2013; Xie, 2011). Cohen and Cohen (2012: 1296) define authentication as a 'process by which something-a role, product, site, object or event-is confirmed as "original", "genuine", "real" or "trustworthy"'. Drawing on Selwyn (1996), Cohen and Cohen (2012) further distinguished between 'hot' and 'cool' modes of authentication, which involve different logics and qualification processes.

Selwyn (1996) originally distinguished between hot and cool authenticity according to the perspective being considered in evaluating tourism experiences and the motivation driving the evaluation process. Hot authenticity centres on tourists' 'imagined world' (1996: 20-21) as they seek to find or experience authentic selves and authentic others in tourism. Hot authenticity is thus concerned with the subjective experience of seeking and encountering tourist places and sociality. Cool authenticity concerns 'propositions' and evaluations about people, places, cultures, objects and experiences that seek to 'claim a different kind of legitimacy' (21) based on rationality and often mobilising various forms of empirical evidence. Cool authenticity is detached, 'etic', making claims about authenticity for some political or economic purpose as destinations and objects are mobilised as resources.

Cohen and Cohen (2012) draw a 'parallel distinction' in seeking to understand different processes of authentication, while shifting the focus from 'socio-psychological concern with the tourists' experiences ... [to] social and political processes' (1297) involved in designating value to tourist activities and attractions. Cool authentication refers to the explicit, formal designation and 'fixing' of qualities, in a particular moment. These performative acts may draw upon 'authoritative' expertise, which is underpinned by scientific, religious or political knowledge claims. Such claims may in turn be legitimised by organisations and institutions that are trusted to have credible authority. Hot authentication, in contrast, draws upon emotive expressions of value associated with places, objects and behaviours. These are emergent claims regarding the hedonic qualities of sites and actions, which are 'reiterated' by actors over time as they continue to perform rituals and engage in embodied experiences (Cohen \& Cohen, 2012).

Cohen and Cohen (2012) argue that hot and cool authentication can operate in isolation or in combination. However, both are conceived as performative acts, which may involve people, objects, technologies and institutions. Authentication emerges through networks of relations as different actors mobilise resources in their attempt to make claims about the qualities of experiences, spaces and artefacts. This suggests that claims are open to contestation as different actors, institutions or even objects have power to shape how assertions of authenticity are made and qualified.

Conceiving tourism-related authentication as socio-material processes, involving hot and cool techniques, has clear linkages with the market practices/ANT approach being advocated here. First, this helps to emphasise that authenticity is not the fixed property of objects or quality of experiences; rather, authenticity emerges as a series of 'value claims'. Second, the conceptual distinction between hot and cool modes of authentication point to 
different inscription processes to make claims about value. Third, authenticity value claims are not considered the exclusive output or product of a singular actor (i.e. one person, organisation, algorithmic computing application or technological device) but emerge through socio-material relations, which points to the need to examine how different actors are enrolled and deployed in valuation processes.

Recent studies applying Cohen and Cohen's (2012) framework in examining authentication in tourism have opened up several lines of enquiry (Frisvoll, 2013; Lamont, 2014; Mkono, 2013). Frisvoll (2013) and Lamont (2014) point to the need to explore further the performative qualities of materiality within authentication processes. Lamont (2014) and Mkono (2013) also highlight the need to consider how social media technologies shape how authentication claims are produced and communicated. The framework advocated in this current paper seeks to account for the performative qualities of materiality and of social media within authentication. In order to do this, the next section examines the complex interaction between technologies and sociality.

\section{Technology and human interaction}

The new millennium has seen the rapid expansion and omnipresence of technology and increasing technological convergence, i.e. the integration of personal communication, image and sound capture and data distribution, through mobile devices. This technological permeation has shaped and is shaped by cultural shifts towards networked sociality (Wittel, 2001). As Wittel notes, social relations are 'informational', based on an 'exchange of data' and 'constructed on the grounds of communication and transport technology' (2001: 51).

Changing societal relations and norms are intimately tied to communication technology: there is blurring between the embodied individual, mobile technology and broader society. As Turkle observed: 'our new intimacy with communication devices compels us to speak of a new state of self' (2008: 121). Turkle proposes the notion of the 'tethered self' - always connected metaphorically and physically to (and through) our electronic devices. Turkle (2008) goes further, conceiving people as fundamentally hybrid entities, blurring the divide between the human and non-human, analogous to ANT conceptions.

Technological convergence and omnipresence has undoubtedly led to a complex and multifaceted relationship between human behaviour and technology (Gillespie, 2014). Souza, Da Silva, Da Silva, Roazzi, \& Da Silva Carrilho (2012), drawing on Hutching (1995), attempt to conceptualise these relationships as 'distributed cognition' (2012: 2322): pervasive computing technologies and increasingly sophisticated computing algorithms have enabled humans to expand their cognitive ability by using external resources to access, manipulate and utilise information. Moreover, social interaction, deploying mental and behavioural capacities, enables humans to develop and distribute knowledge that extends beyond the individual. Importantly, Souza et al. (2012) acknowledge the ongoing interactions between internal cognitive processes and social, cultural and technological 'mechanisms'. Human cognition and non-human algorithms are thus inseparable in social and cultural processes, including those concerned with tourism authentication.

Notions of collective and mediated thinking and remembering, involving external objects, devices and materiality, have been explored by a number of authors (cf. Lury, 1998; Van Dijk, 2007). Landberg (2004: 15) has suggested that 'new technologies of reproduction threaten to dissolve the difference-or an individual's ability to discern the difference- 
between "authentic" and mass-mediated memories, between individual and collective memories'. The driving question for the current discussion is how socio-technological systems become both spaces and processes through which designations of tourism-related authenticity are constructed and qualified. In order to conceptualise the processes of authentication within hybrid human/non-human systems, the discussion draws on the literature on markets and market practices, which is itself part of a broader tradition of ANT (Çalışkan \& Callon, 2010; Callon \& Muniesa, 2005; Callon et al., 2002; Muniesa et al., 2007). The adoption of this approach, referred to hereafter as 'market practices', is useful and necessary in the current discussion for a number of reasons. Firstly, this perspective acknowledges the interaction of multiple agencies in exchange relations, which involve distinguishing between tradable 'goods', qualifying their value and enabling a system for transactions. Secondly, the importance of human and non-human actors or actants, including technologies, is a central characteristic of their approaches to market practices. Thirdly, in recognising the diffused nature of market practices and its networked dynamics, this perspective places emphasis on the processes through which 'things' (values, transactions etc.) are enacted and continue to operate.

\section{Conceptualising market practices}

Çalışkan \& Callon (2010) argue that markets should be conceptualised as performative practices. Markets are: 'sociotechnical arrangements or assemblages ... of heterogeneous constituents that deploy ...: rules and conventions; technical devices; metrological systems; logistical infrastructures; texts, discourses and narratives (e.g. on the pros and cons of competition); technical and scientific knowledge (including social scientific methods), as well as the competencies and skills embodied in living beings ... [to] organize the conception, production and circulation of goods' (Çalışkan \& Callon, 2010: 3). The notion of 'goods' as deployed here encompasses goods and services, which can both be traded in markets. As Callon (2007) has argued, it is increasingly difficult and unhelpful to distinguish between them: goods are produced, qualified, traded and consumed alongside and through supporting services (see also Callon et al., 2002). Similarly, tourism is an assemblage of goods, services, transactions and experiences (Van der Duim, 2007). Various actors in the market(ing) transaction process attempt to transform them into comprehendible, and thus tradeable, goods during production and consumption: operators may try to package them; while consumers evaluate one tourist good against others when making purchasing decisions.

Within market practices, human and non-human actors engage in the process of valuation in which the worth of goods and services are decided. Values are negotiated and re-established as market agencies (including producers, intermediaries and consumers) evaluate consumers' needs, the qualities of the goods, alongside other goods, and the ability of goods to fulfil their needs (Cochoy, 2004, 2008). Some of these qualities and values may be quantified, e.g. by assigning a price, but, importantly, many aspects of this decisionmaking cannot be reduced to quantification. Decision-making also utilises heuristic methods, including drawing on past experiences, using contextual cues, relying on proxy indicators, for example culturally meaningful symbols or the advice of other qualifying agencies, and foregrounding particular features that enable comparison against other goods with similar qualities (Cochoy, 2004, 2008). Market practices involve the ongoing, simultaneous performance of multiple forms of valuation. Following Cochoy (2002), Callon 
and Muniesa (2005) suggest blurring the distinction between qualitative decision making and quantitative calculations. Conceptualising valuation and decision making in this way recognises that it is dynamic, subject to contestation and based on the interaction of diverse agencies with disparate capacities and interests. Importantly, for the current discussion, it is possible to argue that tourism objects and experiences are subjected to similar processes of valuation during which authentication claims are made and used to make judgements about value (Baka, 2015).

It was noted in the introduction that, within such conception, power should be understood as being distributed in or enacted through socio-technological arrangements. The ability to exert influence or exercise power in valuation processes is shaped by a) the ability of particular actors to define the qualities of goods through which their worth can be ascribed; b) the ability to define the calculative/calculating repertoires (both knowledge and methods) through which the values of good are evaluated and c) to construct the market arrangements that enable attempts at definition (of qualities and repertoires) to be accepted by other actors, for example consumers, involved in valuation (Kjellberg et al., 2013).

In order for valuation to take place within market practices, 'the entities taken into account have to be detached...moved, arranged and ordered in a single space'; ... they 'are associated with one another and subjected to manipulations and transformations' and 'a result has to be extracted' (Callon \& Muniesa, 2005: 1231). Goods are 'objectified' and subjected to 'individualization' or 'singularization', a defining of their qualities, which make them valuable to consumers who become attached to them and integrate them into their universes (Callon \& Muniesa, 2005). Singularization can also be seen as co-created value creation (Callon et al., 2002): producers position goods in the market place and attempt to construct propositions regarding the benefits of their goods; consumers make judgements about propositions, attributes and their value in relation to their consumption needs. Producers and consumers are engaged in the ongoing articulation of knowledge claims and evaluations. Singularization within market practices thus relies on configuring shared frames of reference and valuation methods, which enable qualification processes to operate (Callon, 1998; Callon et al., 2002; Cochoy, 2004, 2008).

Having outlined this conception of market practices, involving the objectification of goods, a defining of their qualities, and their ordering within socio-technological performative systems to allow their valuation, the aim is to use this approach to understand the authentication of tourism-related objects, practices and experiences. Importantly, I argue that the value of these experiences is calculated and qualified through sociotechnological arrangements. The implication is that no single actor has the power to wholly define authenticity value; nor are any claims stable or beyond contestation; however, various actors attempt to exercise power by engaging in performative practices to rearticulate particular value claims.

\section{Experiential objects and authenticity as 'valued' resource}

As with the valuation of goods and services, authentication in tourism relies on the creation of entities to be evaluated. I propose to call these 'experiential objects'. Experiential objects reflect a singularity: the delineation and packaging of information or knowledge about tourism-related 'things' in a moment in space and time. The creating of objects - objectification - is thus a (re)presentation of people, places, gestures, physical 
objects, sensations, texts and images. Experiential objects may operate at different scales, referring to a destination, a location within a destination, a social encounter, micro-event or object within a specific location. Experiences may be embodied, occurring in a particular space and time, but objectification takes place as these ephemeral moments are captured, ordered and mediated through technology.

Computing and technological algorithms are key to this objectification process insofar as they delineate the object by (en)coding data into indexable packages, making them distinct from other experiential objects, yet organising them so they can be encountered and valued alongside others. Experiential objects may take different forms, for example social media posts, reviews, or some other data packets. Various functions of algorithms are used to organise these objects, for instance 'tagging' social media posts or reviews, referring to a place or venue (e.g. a hotel, restaurant, temple, beach or mountain), a type of activity (e.g. eating, drinking, viewing), or even some emotive label (e.g. joy, excitement, amazement, even fear) (Matsuo, Hashimoto, \& Iwamoto, 2015). Digital classifications are one of many techniques that allow technology providers to organise bundles of data, and relay them to other users within 'recommender systems' (Sharda, 2010).

The ability of technological devices and sorting algorithms to order experiential objects represents one manifestation of performative power in a broader network of value inscription. However, as experiential objects are transferred from individual devices (e.g. mobile phones, tablets and cameras) to internet-based technological networks they are enrolled into global valuing infrastructures. Social media sites, travel review sites (or travel retail sites with review features) and internet search engines index and draw upon a variety of user data packages in extending the ordering and valuation process. Organisations may examine which web links are followed, which sites are visited, time spent on sites, search terms, positive or negative attitudes shown through sharing, 'liking' and rating, semantics of texts, images, and social network interactions (cf. Ball, Haggerty, \& Lyon, 2012; Fuchs Boersma, Albrechtslund, \& Sandoval, 2012; Netzer, Feldman, Goldenberg, \& Fresko, 2012; Trottier, 2012). Data are used to classify people according to behaviours, attitudes and influence, constructing what Cheney-Lippold (2011) called 'algorithmic identities.' Moreover, in creating and designating such identities, data are used to make predictions about behaviour and preference (Turow, 2008).

The ability of data processing institutions to compile, sort and (re)distribute coded experiential objects reflects a crucial performative convergence of power within valuation processes. Organisations deploy vast socio-technological sorting systems, utilising algorithms to calculate where and how information is presented to users (Gillespie, 2014; Matsuo et al., 2015). As Langlois (2013: 100) notes, social media technology 'enables, directs, and channels specific flows of information as well as specific logics of transformation of data into culturally recognizable and valuable signs and symbols. ... It is about enabling and assigning levels of meaningfulness' [emphasis added]. This involves foregrounding certain sites, users, destinations, texts, sounds and images because they are predicted to be of greater value to users. Information is not treated in a neutral way; discriminative algorithms create particular access paths through masses of data (Gerhart, 2004; Hallinan \& Striphas, 2016; Helmond, 2013). Computers learn the preferences of their users, which may create what Pariser (2011) called 'filter bubbles', with searches providing content that complements existing values, opinions, and behaviours.

The algorithmic processing of tourism-related information reflects one part of objectification and singularization of experiential objects; social interaction with websites 
serves to further qualify their value. Studies of tourist behaviour continue to show how consumers engage with internet-based technologies to make travel and purchase related decisions, which can continue throughout the tourism experience (Jacobsen \& Munar, 2012; Lamsfus, Wang, Alzua-Sorzabal, \& Xiang, 2015; Parra-López, Bulchand-Gidumal, GutiérrezTaño, \& Díaz-Armas, 2011; Sparks \& Browning, 2011). Tourists are entangled in the qualification process insofar as they engage in the valuation system.

Tourists continue to enact inscription practices as they delineate and objectify experiential elements, but also as they are involved in the singularisation process of qualifying their characteristics. Importantly, social media sites are performative spaces through which different actors seek to exercise power and assert their authority over value claims. For example, commentators in Osman et al.'s (2014) study engaged in a heated debate in a forum about the authenticity of consuming McDonald's in a tourist destination. While some contributors criticised tourists for eating in McDonald's, others used the debate to make alternative value claims about such practices:

To see the "real China" for example you should visit a Chinese McDonalds and see whole families enjoying a "night out" but of course that's not the "real China" a tourist is looking for. Get impression sometimes that "authentic" in the eyes of the tourists means "confirming the often oldfashioned perception of a country" rather than seeing the real country.... And who's to say that eating at a Tokyo noodle bar dive with a bunch of backpackers provides a more "authentic" experience than chatting with local teenagers over an Ebi Fillet at McDonald's? What matters more than where we eat is how we connect with another culture. (Osman et al., 2014: 245)

Such value claims appear to draw on the logics of hot authenticity/authentication (Cohen \& Cohen, 2012; Selwyn, 1996) insofar as they mobilise emotive arguments to make assertions about the 'existential authenticity' (Wang, 1999) of social encounters in destination consumption experiences. However, such performative value claims simultaneously mobilise reasoning that point to broader concerns about imperialistic judgements about the 'other'. As one forum contributor noted:

Are we about to criticize all those locals for choosing McDonald's, as if we have the right to tell them what is authentic and what is not? The truth is, a local experience is an experience in the country you are in. (Osman et al., 2014: 244-245 [emphasis added])

Such critiques thus also appear to mobilise cool authentication techniques (Cohen \& Cohen, 2012; Selwyn, 1996), using rational (social) scientific arguments in making value claims and in asserting power over the valuation process.

Studies have shown that consumers have greater trust in some opinions and opinion providers because they are deemed to provide fuller or more informed experience-related advice (Kozinets, 1999; Mack Blose, \& Pan, 2008; Lee, Park, \& Han, 2008; Lugosi, Janta, \& Watson, 2012; Munar \& Jacobsen, 2013; Sparks, Perkins, \& Buckley, 2013). However, consumer authentication does not only refer to tourists ascribing qualities to a place, person, event or object; it may also involve providing information and advice with which future travellers can refine their experiences. For example, in discussions of places to visit 
and eat, consumers in Lugosi et al's (2012: 848) study of online food communities reaffirmed the credibility of the venue and provided advice on how visitors can enhance such experiences through personalisation techniques:

I am Burmese and new to Sydney. I have been to several other Burmese restaurants in Asia, UK and US, and I must say I was rather impressed with the food here. It is authentic indeed and the service from Victor and his staff were [sic] impeccable. [...] next time try the wat tan hor and fried radish cake which are both very good and if having the ice kacang make sure you ask for them to put enough rose water. you'll see they put corn in there's [sic]. some pics of the dishes i've had are available to look at [link attached] in my food slideshow.

Such networks of exchange have the potential to authenticate, or more specifically, to inscribe authentic qualities on, future consumption experiences. In this case, tourists using the advice from experienced commentators can enrol services and specialised ingredients (i.e. rose water) to co-create authentic(ated) gastronomic experiences. Furthermore, these exchanges inscribe qualities on the assemblage of the social network, virtual forum and the (expert) contributors to be able to offer similar advice in the future (cf. Jeacle \& Carter, 2011). These assemblages become 'trusted' configurations of knowledge and thus power through which future value claims can be performed.

Co-created performance of expertise reflects growing consumer empowerment and the diffusion of power in valuation processes (Baka, 2015; Mellet, Beauvisage, Beuscart, \& Trespeuch, 2014). However, consumer performance of expertise is subject to appropriation and (re)enrolment by organisations in their value calculations. Network-mediated performances of expertise are also utilised by many content providers, retailers and distributors that attempt to distinguish between experts and non-experts who engage with their sites. Discriminating between reviewers based on their experience and the quality of their advice authenticates their credibility. This in effect legitimates reviewers' ability to authenticate experiential objects in the future. Many recommender systems require reviewers to register and establish legitimate algorithmic identities. Content providers and users can thus scrutinise reviewers' travel history and expert credibility to qualify trustworthiness in the virtual network (Baka, 2015; Jeacle \& Carter, 2011). Content providers may reinforce this qualification process by showing how many posts users have made and how their posts are rated by others users. Producers and consumers thus interact to create the valuation (market) principles, which then inform subsequent decisions regarding quality and value (Orlikowski \& Scott, 2014; Scott \& Orlikowski, 2012), and hence the authenticity of experiential objects.

It is also important to stress consumers' role in the valuation process as they (re)construct experiential objects through media representation (Osman et al., 2014; Pan, MacLaurin, \& Crotts, 2007; Tussyadiah \& Fesenmaier, 2009). The nature of experiences is qualified through purposeful and accidental processes of editing, framing, emphasis and deemphasis (Picken, 2014; Robinson \& Picard, 2009). Tourists sort, catalogue, index, store and delete pictures (Robinson, 2014). Importantly, as Larsen (2008) illustrates, photographic (and any other mediating) technology is a performative actor shaping how experiences are captured (see also Hillman, 2007; Picken, 2014; Scarles \& Lester, 2014). Similarly the computing and network capacity to access, reproduce and augment representations, using 
other media formats or narratives, shapes how experiential objects are created and transmitted (Tussyadiah \& Zach, 2012). Commercial (tourist) service providers and destination marketing organisations also attempt to create experiential objects that may complement or counter those of tourists and locals, but these compete with multiple representations in media consumption spaces (cf. Hays, Page, \& Buhalis, 2012; Tegelberg, 2013; Roque \& Raposo, 2016).

Experiential objects can be considered valued resources. The term 'valued' has two meanings here: it refers to something a) that has been valued, i.e. its worth has been qualified and negotiated through networks of relationships; and b) that is valued, i.e. its worth is appreciated by those who have engaged with it or who wish to in the future. Experiential objects come to have exchange rather than intrinsic use value: they are used by individuals to show their individuality, conformity or belonging, and perform knowledge and competencies (Bosangit, Hibbert, \& McCabe, 2015; Cohen, 2010; Enoch \& Grossman, 2010; Germann Molz, 2012). Data have become valuable tradable commodities for technology companies and content providers for subsequent deployment in segmenting markets, predicting behaviour and refining content provision. Consumer-created content are also valued resources for venues, brands and destinations, partly as they directly authenticate other tourists' experiences (Lugosi, 2014; Osman et al., 2014; Scott \& Orlikowski, 2012), but also because they provide data sets that tourism providers can utilise to refine their offerings and practices (Marine-Roig \& Clavé, 2015; Orlikowski \& Scott, 2015; Stienmetz \& Fesenmaier, 2013; Tussyadiah, 2012). However, it is important to acknowledge the pluralistic and thus contested nature of worth within a networked valuation system. Negative representations, though still experiential objects, can become threats to destinations and tourist organisations. Shakeela and Weaver (2012), for example, mapped the media representations of an incident in the Maldives when a western couple were subjected to a humiliating fake wedding ceremony conducted by hotel employees. Such consumer 'devaluation' prompts organisations to engage in further calculative processes to determine the most appropriate tactical response (Wang, Wezel, \& Forgues, 2015), for instance, whether and how they respond to negative reviews on TripAdvisor.

The production of experiential objects should not be thought of as a linear process; nor should it be seen as a neat, rational system of value creation. There are multiple algorithms at work, with different commercial organisations using independent systems and (algorithmic) methods to monitor and predict the attitudes and behaviours of potential consumers. Furthermore, because this is a socio-technological network of value calculation and qualification, it is subject to a range of social, cultural and computational influences.

The authentic potentials of experiential objects may also be qualified through different mechanisms. Authentication may emerge through the increasing accessibility or visibility of experiential objects through representation. This may take the form of Cohen and Cohen's (2012a) 'hot' authentication, which references hedonic aspects of experience or 'cool' authentication that relies on 'expert' knowledge and such institutional 'devices' as accreditation. Authentication may thus invoke notions of objective and existential authenticity separately or in combination (Reisinger \& Steiner, 2006; Steiner \& Reisinger, 2006). Sensations of communitas or emotive experiences (involving places, people, activities) may be framed and positioned as being authentic because they are increasingly discussed through text or depicted through images (Bosangit et al., 2015; Lugosi, 2014). The foregrounding of excitement, emotion, or notions of liminality can qualify experiential value. 
The qualities of experiences may also be authenticated through their absence or obscuration in representation. Not appearing in travel or popular media, or only appearing in media judged in the social marketplace to have cultural credibility, may be equally strong articulations of the experiential value of places and people. As Gillespie (2014: 172) observes some sites may prevent 'data collectors (like search engines)' to index their content. Organisations and individuals may consciously engage in what Eisenberg (1984) called 'strategic ambiguity' to obscure some aspect of experience as a way to reinforce its privileged position or exclusivity. For example, Dinner en Blanc, an international organisation that hosts pop-up food events, makes the most crucial information about their activities available only to registered members; potential customers have to apply to attend their events and the venues are kept secret.

In all cases, the socio-technological/market practices approach adopted here suggests that the valuation of experiential objects emerges as they are (re)produced in networks and constellations of experiential objects, which allows a) their qualities to be articulated in relation to each other, and $b$ ) the relative worth to be evaluated through these connective associations. Consequently, a mechanism of authentication involves attempts by organisations and individuals to couple and de-couple experiential objects as well as objects, actors, networks and spaces. Coomans (2013), for example, illustrates how religious organisations fuse imagery of monks living in a monastic setting and contemporary food and drink consumption. Textual descriptions of monastic history, practices and values are accompanied by visual depictions of the monks dressed in traditional Cistercian habit, which reflect attempts to coolly authenticate monasteries as places of long-standing tradition, ritual and piety. These representations are placed alongside images of food, gastronomy and social interactions, which seek to hotly authenticate the hospitality experiences available to tourists. Such attempts at authentication strategically assemble multiple aspects of culture and heritage to construct linear relationships between history and the present for consumers (see also Bessiere, 1998; Chhabra, Lee, Zhao, \& Scott, 2013; Lu \& Fine, 1995; MacDonald, 2013; Ren, 2011; Robinson \& Clifford, 2011; Ron \& Timothy, 2013; Schouten, 2006).

The mechanisms or techniques of authentication inevitably coexist and are utilised by various agencies in different combination through the delineation, qualification and valuation of experiential objects. When the interests and techniques converge, they can lead to what we may call 'cumulative authentication' as different agents continue to foreground and connect the same information about experiential objects. This would include, for example, search engines, destination marketers, travel review sites and tourists assigning similar values to the same site or event. Importantly, different human and nonhuman agencies can exercise power in the authentication process, which may stem from their ability to transform and present information, and for this information to be valued by other agents entangled in these networks of relationships. 


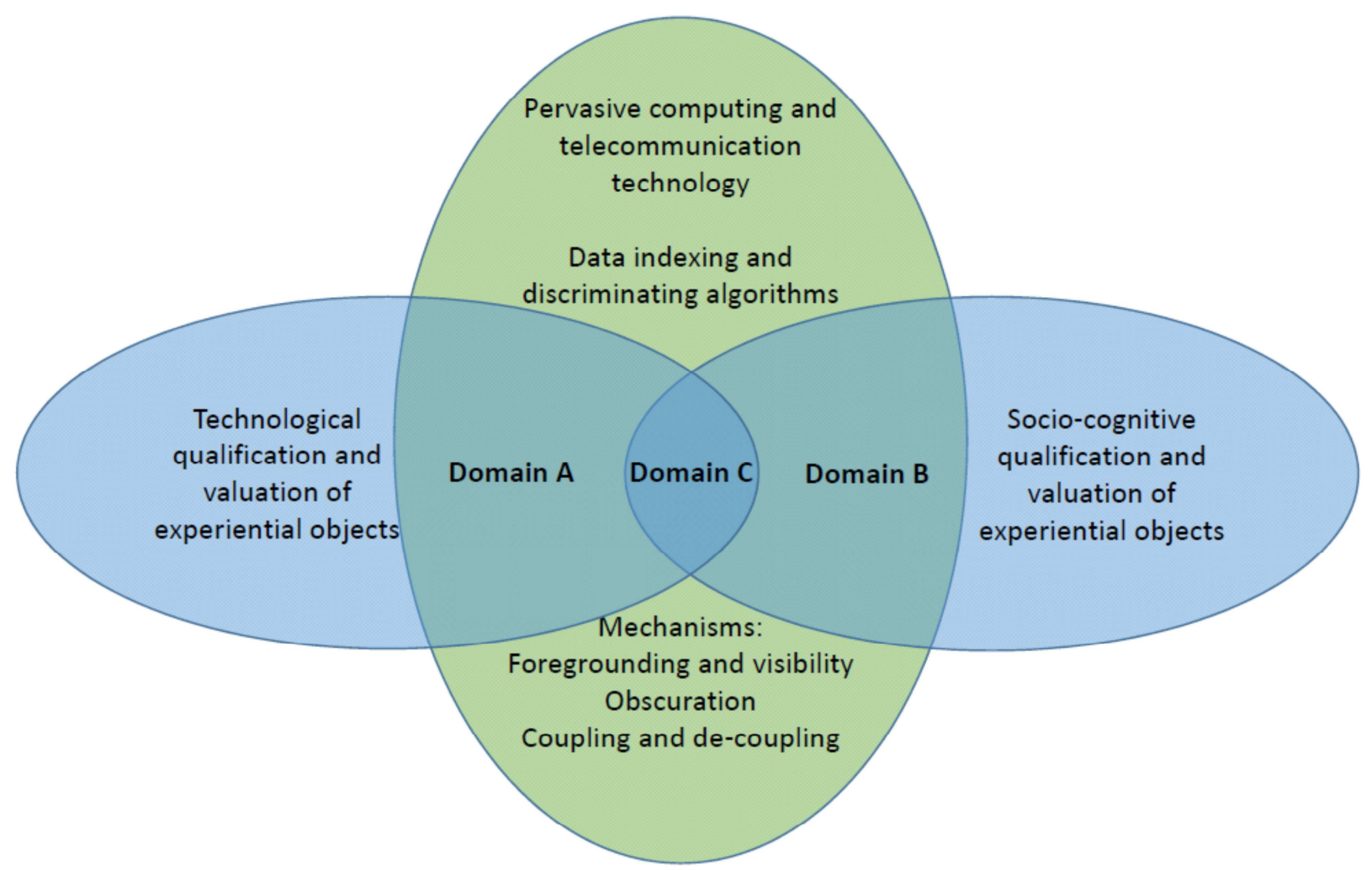

Figure 1. Domains of enquiry in socio-technological authentication

The challenge for future research is to examine how agents interact and utilise different techniques in the authentication process. Figure 1 identifies three different domains of enquiry for subsequent research. An overarching set of questions concern the role of pervasive computing and communications technology, data indexing and discriminative algorithms and the mechanisms of authentication deployed. Domain A focuses on the technological and computational dimensions of objectification and qualification. This reflects research among computer scientists and systems designers who create soft and hardware that seeks to facilitate the production and consumption of tourist experiences in destinations (Matsuo et al., 2015; Sharda, 2010). This research is likely to be highly technical and serving commercial interests in creating and managing consumer demand. Domain B focuses on the social and cognitive dimensions of authentication. In the past, this research has been conducted principally by social scientists who have considered how consumers qualify and evaluate notions of authenticity in destination experiences (Lamont, 2014; Mkono, 2013). However, there is continuing need to examine how technology is utilised, how information regarding experiential objects is stored, processed, evaluated, transformed and reproduced, and the mechanisms through which these objects are authenticated. Importantly, Domain $C$ reflects the opportunity to open up a further body of interdisciplinary research that understands, in more complex ways, how human and computing technologies and techniques interact within the construction of experiential objects and the performance of authentication. There is scope within such research to mobilise technical expertise of systems and behaviours that makes empirically apprehendable the mechanism through which experiential objects are assembled and their value is negotiated. 


\section{Conclusion}

This paper has proposed a socio-technological approach to conceptualising authentication. Drawing on an ANT approach and a market practices perspective, it has argued that authentication within contemporary technology-saturated society is produced or performed through socio-technological arrangements. The paper has also outlined a number of defining elements within these arrangements, including the creation of experiential objects that are delineated from other objects, but are produced alongside and in relation to others, enabling their value to be calculated. Moreover, the paper has argued that the nature and worth of experiential objects are qualified and re-qualified through the interaction of human and non-human actors. The paper has also suggested various mechanisms within these socio-technical arrangements through which authentication may operate, including foregrounding and visibility, invisibility or ambiguity, and selective coupling/de-coupling. These processes and mechanisms may be used in 'hot' and 'cool' authentication (Cohen \& Cohen, 2012a) and in making claims regarding object and existential authenticity.

In contrast to existing work, which has stressed the role of power exercised by consumers, governments, 'experts' and commercial organisations, the paper has suggested a view of power as being distributed and exercised by multiple actors in socio-technological arrangements. Whilst this perspective acknowledges human agency and the capacity for people to be a part of the experience objectification and qualification process, it also recognises the role of technological organisations and systems, and the algorithmic capacities they deploy in the authentication process. The opportunity, and challenge, for future research is to draw on market practices and ANT approaches to examine empirically the processes of authentication in situ. An interdisciplinary approach to such endeavour may utilise expertise from computer science alongside social scientists working in sociology, psychology, anthropology and geography to identify how pervasive computing technology and algorithmic data processing can shape how consumers encounter people, places and objects, thus shaping their conceptions of authenticity. Moreover, how their interaction with technology subsequently feeds into authentication processes.

\section{References}

Baka, V. (2015). Understanding valuing devices in tourism through "place-making". Valuation Studies, 3(2), 149-180.

Ball, K., Haggerty, K. D., \& Lyon, D. (Eds.). (2012). Routledge handbook of surveillance studies. Abingdon: Routledge.

Belhassen, Y., \& Caton, K. (2006). Authenticity matters. Annals of Tourism Research, 33(3), 853-856.

Belhassen, Y., Caton, K., \& Stewart, W. P. (2008). The search for authenticity in the pilgrim experience. Annals of Tourism Research, 35(3), 668-689.

Bessière, J. (1998). Local development and heritage: Traditional food and cuisine as tourist attractions in rural areas. Sociologia Ruralis, 38(1), 21-34.

Bosangit, C., Hibbert, S., \& McCabe, S. (2015). "If I was going to die I should at least be having fun": Travel blogs, meaning and tourist experience. Annals of Tourism Research, 55, 1-14.

Brown, L. (2013). Tourism: A catalyst for existential authenticity. Annals of Tourism Research, 40, 176-190. 
Çalışkan, K., \& Callon, M. (2010). Economization, part 2: A research programme for the study of markets. Economy \& Society, 39(1), 1-32.

Callon, M. (1998). An essay on framing and overflowing: Economic externalities revisited by sociology. The Sociological Review, 46(S1), 244-269.

Callon, M. (2007). An essay on the growing contribution of economic markets to the proliferation of the social. Theory, Culture \& Society, 24(7-8), 139-163.

Callon, M., \& Muniesa, F. (2005). Economic markets as calculative collective devices. Organization Studies, 26(8), 1229-1250.

Callon, M., Méadel, C., \& Rabeharisoa, V. (2002). The economy of qualities. Economy \& Society, 31(2), 194-217.

Cheney-Lippold, J. (2011). A new algorithmic identity: Soft biopolitics and the modulation of control. Theory, Culture \& Society, 28(6), 164-181.

Chhabra, D. (2005). Defining authenticity and its determinants: Toward an authenticity flow model. Journal of Travel Research, 44(1), 64-73.

Chhabra, D. (2010). Back to the past: A sub-segment of Generation Y's perceptions of authenticity. Journal of Sustainable Tourism, 18(6), 793-809.

Chhabra, D. (2012). Authenticity of the objectively authentic. Annals of Tourism Research, 39(1), 499-502.

Chhabra, D., Lee, W., Zhao, S., \& Scott, K. (2013). Marketing of ethnic food experiences: Authentication analysis of Indian cuisine abroad. Journal of Heritage Tourism, 8(2-3), 145-157.

Cochoy, F. (2002). Une sociologie du packaging, ou l'âne de Buridan face au marché. Paris: Presses Universitaires de France.

Cochoy, F. (2004). Is the modern consumer a Buridan's donkey? Product packaging and consumer choice. In K. Ekström, \& H. Brembeck (Eds.), Elusive consumption (pp. 205227). Oxford: Berg.

Cochoy, F. (2008). Calculation, qualculation, calqulation: Shopping cart arithmetic, equipped cognition and the clustered consumer. Marketing Theory, 8(1), 15-44.

Cohen, S. (2010). Chasing and myth?. Searching for 'self' through lifestyle travel. Tourist Studies, 10(2), 117-133.

Cohen, E., \& Cohen, S. A. (2012a). Authentication: Hot and cool. Annals of Tourism Research, 39(3), 1295-1314.

Coomans, T. (2013). Identity ambivalences of monastic heritage and international networks: The case of the Cistercians and Trappists. In D. Callebaut, J. Mařík, \& J. MaříkováKubková (Eds.), Heritage reinvents Europe. Proceedings of the 12th EAC Symposium, Ename 17-19 March 2011 (pp. 93-100). Ename: Europae Archaeologiae Consilium.

Eisenberg, E. M. (1984). Ambiguity as strategy in organizational communication. Communication Monographs, 51(3), 227-242.

Enoch, Y., \& Grossman, R. (2010). Blogs of Israeli and Danish backpackers to India. Annals of Tourism Research, 37(2), 520-536.

Frisvoll, S. (2013). Conceptualising authentication of ruralness. Annals of Tourism Research, 43, 272-296.

Frochot, I., \& Batat, W. (2013). Marketing and designing the tourist experience. Oxford: Goodfellow Publishers.

Fuchs, C., Boersma, K., Albrechtslund, A., \& Sandoval, M. (Eds.). (2012). Internet and surveillance: The challenges of Web 2.0 and social media. Abingdon: Routledge. 
Gerhart, S. (2004). Do Web search engines suppress controversy?. First Monday, 9(1), Article 3 [online], DOI: http://dx.doi.org/10.5210/fm.v9i1.1111.

Germann Molz, J. G. (2012). Travel connections: Tourism, technology, and togetherness in a mobile world. Abingdon: Routledge.

Gillespie. T. (2014). The relevance of algorithms. In: T. Gillespie, P. Boczkowski, \& K. Foot (Eds.), Media technologies: Essays on communication, materiality, and society (pp. 167-194). Cambridge, MA: MIT Press.

Hays, S., Page, S. J., \& Buhalis, D. (2012). Social media as a destination marketing tool: Its use by national tourism organisations. Current Issues in Tourism, 16, 211-239.

Hallinan, B., \& Striphas, T. (2016). Recommended for you: The Netflix Prize and the production of algorithmic culture. New Media \& Society, 18(1), 117-137.

Helmond, A. (2013). The algorithmization of the hyperlink. Computational Culture, 3(3), [Online], http://computationalculture.net/article/the-algorithmization-of-thehyperlink.

Hillman, W. (2007). Travel authenticated?: Postcards, tourist brochures, and travel photography. Tourism Analysis, 12(3), 135-148.

Hutchins, E. (1995). Cognition in the wild. Cambridge, MA: MIT Press.

Jacobsen, J. K. S., \& Munar, A. M. (2012). Tourist information search and destination choice in a digital age. Tourism Management Perspectives, 1, 39-47.

Jeacle, I., \& Carter, C. (2011). In TripAdvisor we trust: Rankings, calculative regimes and abstract systems. Accounting, Organizations \& Society, 36(4), 293-309.

Jóhannesson, G. T. (2005). Tourism translations: Actor-network theory and tourism research. Tourist Studies, 5(2), 133-150.

Jóhannesson, A. P. G. T., van der Duim, R., \& Ren, M. C. (Eds.). (2015). Tourism encounters and controversies: Ontological politics of tourism development. Farnham: Ashgate.

Kim, H., \& Jamal, T. (2007). Touristic quest for existential authenticity. Annals of Tourism Research, 34(1), 181-201.

Kjellberg, H., Mallard, A., Arjaliès, D. L., Aspers, P., Beljean, S., Bidet, A., ... \& Hoeyer, K. (2013). Valuation studies? Our collective two cents. Valuation Studies, 1(1), 11-30.

Kozinets, R. V. (1999). E-tribalized marketing?: The strategic implications of virtual communities of consumption. European Management Journal, 17(3), 252-264.

Lamont, M. (2014). Authenticating sport tourism. Annals of Tourism Research, 45, 1-14.

Lamsfus, C., Wang, D., Alzua-Sorzabal, A., \& Xiang, Z. (2015). Going mobile defining context for on-the-go travelers. Journal of Travel Research, 54(6), 691-701.

Landsberg, A. (2004). Prosthetic memory: The transformation of American remembrance in the age of mass culture. New York: Columbia University Press.

Langlois, G. (2013). Participatory culture and the new governance of communication: The paradox of participatory media. Television \& New Media, 14(2), 91-105.

Latour, B. (2005). Reassembling the social: An introduction to actor-network-theory. Oxford: Oxford University Press.

Larsen, J. (2008). Practices and flows of digital photography: An ethnographic framework. Mobilities, 3(1), 141-160.

Lau, R. W. (2010). Revisiting authenticity: A social realist approach. Annals of Tourism Research, 37(2), 478-498.

Lee, J., Park, D. H., \& Han, I. (2008). The effect of negative online consumer reviews on product attitude: An information processing view. Electronic Commerce Research \& Applications, 7(3), 341-352. 
Lu, S., \& Fine, G. A. (1995). The presentation of ethnic authenticity: Chinese food as a social accomplishment. The Sociological Quarterly, 36(3), 535-553.

Lugosi, P. (2014). Mobilising identity and culture in experience co-creation and venue operation. Tourism Management, 40, 165-179.

Lugosi, P., Janta, H., \& Watson, P. (2012). Investigative management and consumer research on the internet. International Journal of Contemporary Hospitality Management, 24(6), 838-854.

Lury, C. (1998). Prosthetic culture: Photography, memory and identity. Abingdon: Routledge.

MacCannell, D. (1999). The tourist: A new theory of the leisure class. Berkeley: University of California Press.

MacDonald, K. I. (2013). The morality of cheese: A paradox of defensive localism in a transnational cultural economy. Geoforum, 44, 93-102.

Mack, R. W., Blose, J. E., \& Pan, B. (2008). Believe it or not: Credibility of blogs in tourism. Journal of Vacation Marketing, 14(2), 133-144.

Marine-Roig, E., \& Clavé, S. A. (2015). Tourism analytics with massive user-generated content: A case study of Barcelona. Journal of Destination Marketing \& Management, DOI: 10.1016/j.jdmm.2015.06.004.

Martin, K. (2010). Living pasts: Contested tourism authenticities. Annals of Tourism Research, 37(2), 537-554.

Matsuo, T., Hashimoto, K., \& Iwamoto, H. (Eds.). (2015). Tourism informatics: Towards novel knowledge based approaches. Berlin: Springer.

Mellet, K., Beauvisage, T., Beuscart, J. S., \& Trespeuch, M. (2014). A “democratization" of markets? Online consumer reviews in the restaurant industry, Valuation Studies, 2(1), 5-41.

Mkono, M. (2012a). Authenticity does matter. Annals of Tourism Research, 39(1), 480-483.

Mkono, M. (2012b). A netnographic examination of constructive authenticity in Victoria Falls tourist (restaurant) experiences. International Journal of Hospitality Management, 31(2), 387-394.

Mkono, M. (2013). Hot and cool authentication: A netnographic illustration. Annals of Tourism Research, 41, 215-218.

Munar, A. M., \& Jacobsen, J. K. S. (2013). Trust and involvement in tourism social media and web-based travel information sources. Scandinavian Journal of Hospitality \& Tourism, 13(1), 1-19.

Muniesa, F., Millo, Y., \& Callon, M. (2007). An introduction to market devices. The Sociological Review, 55(s2), 1-12.

Netzer, O., Feldman, R., Goldenberg, J., \& Fresko, M. (2012). Mine your own business: Market structure-surveillance through text mining. Marketing Science, 31(3), 521-543.

Olsen, K. (2002). Authenticity as a concept in tourism research: The social organization of the experience of authenticity. Tourist studies, 2(2), 159-182.

Orlikowski, W. J., \& Scott, S. V. (2014). What happens when evaluation goes online?: Exploring apparatuses of valuation in the travel sector. Organization Science, 25(3), 868-891.

Orlikowski, W. J., \& Scott, S. V. (2015). Exploring material-discursive practices. Journal of Management Studies, 52(5), 697-705.

Osman, H., Johns, N., \& Lugosi, P. (2014). Commercial hospitality in destination experiences: McDonald's and tourists' consumption of space. Tourism Management, 42, 238-247. 
Paget, E., Dimanche, F., \& Mounet, J. P. (2010). A tourism innovation case: An actor-network approach. Annals of Tourism Research, 37(3), 828-847.

Pan, B., MacLaurin, T., \& Crotts, J. C. (2007). Travel blogs and the implications for destination marketing. Journal of Travel Research, 46(1), 35-45.

Pariser, E. (2011). The filter bubble: What the Internet is hiding from you. London: Penguin.

Parra-López, E., Bulchand-Gidumal, J., Gutiérrez-Taño, D., \& Díaz-Armas, R. (2011). Intentions to use social media in organizing and taking vacation trips. Computers in Human Behavior, 27(2), 640-654.

Picken, F. (2014). 'So much for snapshots': The material relations of tourists as cultural dupes. Tourist Studies, 14(3), 246-260.

Pine J.P., \& Gilmore, J.H. (2008). The eight principles of strategic authenticity. Strategy \& Leadership, 36(3), 35-40.

Ren, C. (2011). Non-human agency, radical ontology and tourism realities. Annals of Tourism Research, 38(3), 858-881.

Reisinger, Y., \& Steiner, C. J. (2006). Reconceptualizing object authenticity. Annals of Tourism Research, 33(1), 65-86.

Robinson, M., \& Picard, D. (Eds.). (2009). The framed world: Tourism, tourists and photography. Farnham: Ashgate Publishing.

Robinson, P. (2014). Emediating the tourist gaze: Memory, emotion and choreography of the digital photograph. Information Technology \& Tourism, 14(3), 177-196.

Robinson, N., \& Clifford, C. (2011). Authenticity and festival foodservice experiences. Annals of Tourism Research, 39(2), 571-600.

Ron, A. S., \& Timothy, D. J. (2013). The land of milk and honey: Biblical foods, heritage and Holy Land tourism. Journal of Heritage Tourism, 8(2-3), 234-247.

Roque, V., \& Raposo, R. (2016). Social media as a communication and marketing tool in tourism: An analysis of online activities from international key player DMO, Anatolia, 27(1), 58-70.

Scarles, C., \& Lester, J.A. (Eds.). (2014). Mediating the tourist experience: From brochures to virtual encounters. Farnham: Ashgate.

Shakeela, A., \& Weaver, D. (2012). Resident reactions to a tourism incident: Mapping a Maldivian Emoscape. Annals of Tourism Research, 39(3), 1337-1358.

Sharda, N. (Ed.). (2010). Tourism informatics: Visual travel recommender systems, social communities, and user interface design. Hershey, NY: IGI Global.

Schouten, F. (2006). The process of authenticating souvenirs. In M. K. Smith \& M. Robinson (Eds.), Cultural tourism in a changing world: Politics, participation and (Re) presentation (pp. 191-202). Bristol: Channel View Publications.

Scott, S. V., \& Orlikowski, W. J. (2012). Reconfiguring relations of accountability: Materialization of social media in the travel sector. Accounting, Organizations \& Society, 37(1), 26-40.

Selwyn, T. (1996). Introduction. In T. Selwyn (Ed.), The tourist image: Myth and mythmaking in tourism (pp. 1-32). Chichester: Wiley.

Souza, B. C., Da Silva, A. S., Da Silva, A. M., Roazzi, A., \& da Silva Carrilho, S. L. (2012). Putting the Cognitive Mediation Networks Theory to the test: Evaluation of a framework for understanding the digital age. Computers in Human Behavior, 28(6), 2320-2330.

Sparks, B. A., \& Browning, V. (2011). The impact of online reviews on hotel booking intentions and perception of trust. Tourism Management, 32(6), 1310-1323. 
Sparks, B. A., Perkins, H. E., \& Buckley, R. (2013). Online travel reviews as persuasive communication: The effects of content type, source, and certification logos on consumer behavior. Tourism Management, 39, 1-9.

Steiner, C. J., \& Reisinger, Y. (2006). Understanding existential authenticity. Annals of Tourism Research, 33(2), 299-318.

Stienmetz, J. L. \& Fesenmaier, D. R. (2013). Traveling the network: A proposal for destination performance metrics. International Journal of Tourism Sciences, 13(2), 57-75.

Tegelberg, M. (2013). Framing Maya culture: Tourism, representation and the case of Quetzaltenango. Tourist Studies, 13(1), 81-98.

Tribe, J. (2010). Tribes, territories and networks in the tourism academy. Annals of Tourism Research, 37(1), 7-33.

Trottier, D. (2012). Social media as surveillance: Rethinking visibility in a converging world. Farham: Ashgate Publishing.

Turkle, S. (2008). Always-on/always-on-you: The tethered self. In J. Katz (Ed.), Handbook of mobile communication and social change (pp. 121-137). Cambridge, MA: MIT Press.

Turow, J. (2008). Niche envy: Marketing discrimination in the digital age. Cambridge, MA: MIT Press.

Tussyadiah, I. P. (2012). A concept of location-based social network marketing. Journal of Travel \& Tourism Marketing, 29(3), 205-220.

Tussyadiah, I. P., \& Fesenmaier, D. R. (2009). Mediating tourist experiences: Access to places via shared videos. Annals of Tourism Research, 36(1), 24-40.

Tussyadiah, I. P., \& Zach, F. J. (2012). The role of geo-based technology in place experiences. Annals of Tourism Research, 39(2), 780-800.

Van der Duim, R. (2007). Tourismscapes: An actor-network perspective. Annals of Tourism Research, 34(4), 961-976.

Van der Duim, R., Ren, C., \& Jóhannesson G. T. (Eds.) (2012). Actor-network theory and tourism: Ordering, materiality and multiplicity. London: Routledge.

Van der Duim, R., Ren, C., \& Jóhannesson, G. T. (2013). Ordering, materiality and multiplicity: Enacting ANT in tourism. Tourist Studies, 13(1), 3-20.

Van Dijck, J. (2007). Mediated memories in the digital age: Cultural memory in the present. Stanford: Stanford University Press.

Wang, N. (1999). Rethinking authenticity in tourism experience. Annals of Tourism Research, 26(2), 349-370.

Wang, Y. (2007). Customized authenticity begins at home. Annals of Tourism Research, 34(3), 789-804.

Wang, T., Wezel, F. C., \& Forgues, B. (2015). Protecting market identity: When and how do organizations respond to consumers' devaluations. Academy of Management Journal, DOI: $10.5465 / a m j .2014 .0205$.

Wittel, A. (2001). Toward a network sociality. Theory, Culture \& Society, 18(6), 51-76.

Xie, P. F. (2011). Authenticating ethnic tourism. Bristol: Channel View Publications.

Xie, P. F., \& Wall, G. (2002). Visitors' perceptions of authenticity at cultural attractions in Hainan, China. International Journal of Tourism Research, 4(5), 353-366. 